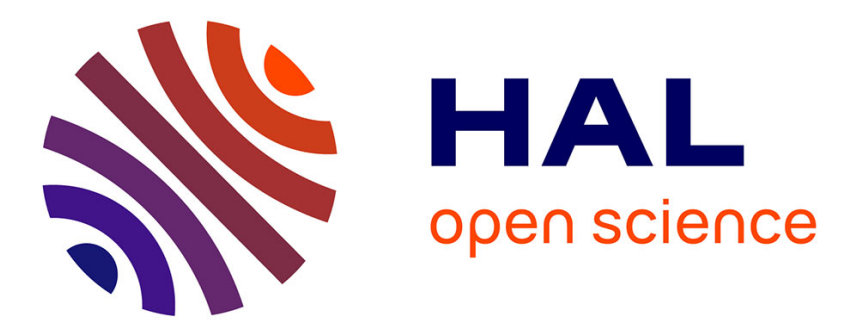

\title{
Thermal analysis of interpenetrating polymer networks through molecular dynamics simulations: a comparison with experiments
}

Kamel Boudraa, Tewfik Bouchaour, Ulrich Maschke

\section{- To cite this version:}

Kamel Boudraa, Tewfik Bouchaour, Ulrich Maschke. Thermal analysis of interpenetrating polymer networks through molecular dynamics simulations: a comparison with experiments. Journal of Thermal Analysis and Calorimetry, 2019, 140 (4), pp.1845-1857. 10.1007/s10973-019-08898-y . hal02377047

\section{HAL Id: hal-02377047 \\ https://hal.univ-lille.fr/hal-02377047}

Submitted on 7 Jan 2021

HAL is a multi-disciplinary open access archive for the deposit and dissemination of scientific research documents, whether they are published or not. The documents may come from teaching and research institutions in France or abroad, or from public or private research centers.
L'archive ouverte pluridisciplinaire HAL, est destinée au dépôt et à la diffusion de documents scientifiques de niveau recherche, publiés ou non, émanant des établissements d'enseignement et de recherche français ou étrangers, des laboratoires publics ou privés. 


\title{
Thermal analysis of interpenetrating polymer networks through molecular dynamic simulations: A Comparison with Experiments
}

\author{
Kamel Boudraa $^{1,2}$, Tewfik Bouchaour ${ }^{2}$, Ulrich Maschke ${ }^{3}$ \\ 1 Biology Department, Faculty of Sciences, University of Saida, Algeria (boudraa.kamel@univ-saida.dz, \\ https://orcid.org/0000-0001-8045-0586)
}

2 Laboratoire de Recherche sur les Macromolécules, Département de Physique, Faculté des Sciences, Université Abou Bakr Belkaïd, Tlemcen, Algeria.

3 Unité de Matériaux et de Transformations UMET (UMR CNRS N8207), Bâtiment C6, Université des

Sciences et Technologies de Lille, F-59655 Villeneuve d'Ascq Cedex, France

\section{Abstract :}

In this work, we verified the synthesis of a novel sequential interpenetrating polymer network (IPN), composed of poly(2-hexyl-ethylacrylate) and poly(n-butyl acrylate) named PHEA and PBuA respectively, and we studied the physical properties by means of Thermogravimetric Analysis (TG) and Differential Scanning Calorimetry (DSC) techniques. It's found an increase in the thermal stability with the increase of the density of the polymer network and the amount of the absorbed monomer by the network has a great influence on its behavior and glass transition temperature. We supplement this job by applying Molecular Dynamics simulation methods (free volume, radial distribution function) to investigate the properties of these polymer networks and effects of composition ratios and temperature by introducing a new comprehensive and reproducible atomistic model for the generation and property evaluation of interpenetrating polymer networks. The simulation presented from the discontinuity in the different plots versus temperature of the specific volume or radial distribution function, demonstrates that the glass transition temperature $\left(T_{\mathrm{g}}\right)$ values were in good agreement with experimental values.

\section{Key words:}

Interpenetrating Polymer Network, Thermal analysis, Atomistic simulation, Glass transition

\section{Article Highlights}

- Synthesis of new interpenetrating polymer network systems

- Thermal characterization and determination of physical properties

- Confrontation and comparison of theory with experience

\section{Acknowledgments}

- $\quad$ The author thank the members of CULGI ${ }^{\circledR}$ for their continued support

- This work was granted access to the HPC ressources of UCI-UABT "Unité de Calcul Intensif" of the University Abou bekr Belkaïd of Tlemcen financed by the DGRSDT "Direction Générale de la recherche Scientifique et du Développement Technologique“

Kamel Boudraa : boudraa.kamel@univ-saida.dz 


\section{Introduction :}

Atomistic molecular modelling are a very interesting tool to have preliminary information about blends, phase behavior and compatibility, which exist between polymers [1-2]. They are an alternative solution to researchers who have not access to experimental. They have reached, recently [3-10], a very high level of sophistication, to the point of being able to predict easily several properties with a very high precision, thus anticipating the possible applications of the modelled systems. The choice of the modeling method depends on the system studied. Indeed, several methods are available; we can say the stochastic (Monte-Carlo simulations) or quantum (ab-initio) methods and the molecular dynamics method [11-13]. This last is used in when the studied system contains a considerable size of the molecular chains (more than 1300 atoms in a polymer chain) while for other methods the number of atoms is limited [14-18]. Indeed, molecular dynamics is a deterministic method; the propagation of the system is done by applying the classical equations of the movement of the particles. This technique makes it possible to obtain so many structural characteristics as dynamic characteristics relating to the modeled system [19-20].

The common of polymer material blending processes leads generally to the combination of thermodynamically incompatible compounds [21-22]. Thus, the synthesis of interpenetrating polymer networks (IPNs) has become a consistent development path to obtain a polymer network that is stable over time [23]. This synthesis corresponds to the combination of crosslinked polymers of which at least one is synthesized in the immediate presence of the other. This allows combining within a single material the different properties of the two precursor networks while covering the deficiencies of each of them [24]. IPNs are dimensionally and thermally stable over time [25-28] and may have improved properties of resistance to chemical and physical aging. One of the main interesting properties to consider when studying IPNs systems is their thermal properties. Recently, many scientific reports have been focused on synthesis [29-39] and thermal properties of polymer blends [40$44]$, on the other hand on the observation, the characterization and the improvement of the interfaces and interphases present within such mixtures or of composites [45-48]. The relationships structure-property of interpenetrating polymer networks has sometimes been discussed in experiments, but without a theoretical study being accompanied in parallel. The originality of this work is due to the variety of systems studied according to the same type of model, but also to experimental measurements, which are confronted with modeling data (simulation). This type of study, for interpenetrating polymer networks, is little reported in the literature which encouraged us to start it. Indeed, we present experimental and theoretical study of synthesis of novel interpenetrating polymer networks based on Poly Hexyl-Ethyl-Acrylate (PHEA) and Poly Butyl-Acrylate (PBuA) networks. The choice of these two polymers is due to their various potential utilizations. Indeed, the 2Ethylhexyl acrylate (HEA) is a very useful monomer for many industrial applications. It is marked essentially by his low glass transition temperature $\left(\mathrm{Tg}=-65^{\circ} \mathrm{C}\right)$ and has very good film formation property [49]. Poly $(2-$ ethylhexyl acrylate) (PHEA), are widely used in many applications [50]. The copolymers of PHEA with other acrylates, methacrylates, acrylonitrile, maleic acid esters, vinyl acetate, vinyl chloride, etc. find applications in adhesives, chemical intermediates, coatings, leather, plasticizers, plastics and textiles [51]. The Poly(n-butyl acrylate) ( $\mathrm{PBuA}$ ) can be used as a soft segment in thermoplastic elastomers due to its low glass transition temperature and durability [52]. It is a very ductile ( 2000\% elongation at break), sticky, colorless and transparent rubbery material [53]. In view of their complementary properties, blending PBuA with PHEA is a natural choice to improve properties including ductility without compromising transparency. The realization of 
IPN systems will be checked step by step by giving a detailed analysis of the swelling kinetics of the different networks in the reactive solution containing monomer and crosslinker and a detailed simulation of formation of these networks. Information about the glass transitions temperature of the resulting IPNs and TG/DTG curves are also presented and compared with their precursory networks.

\section{Experimental part:}

\section{Monomers:}

The monomers, n-butyl-acrylate (99\%) and 2-hexyl-ethylacrylate (98\%), designated (n-BuA) and (2-HEA) respectively, were obtained from Aldrich. 1,6-Hexanedioldiacrylate (HDDA), supplied by Cray Valley (France) is used as crosslinking agent. 2-hydroxy-2-methyl-1-phenyl-propane-1 (Darocur 1173) from Ciba-Geigy was used as a photo-initiator.

\section{Sample preparation:}

Prepolymers synthesis:

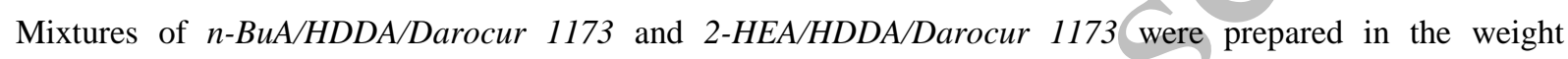
fractions $99 / 0.5 / 0.5 \mathrm{wt} \%$. The initial mixtures were stirred mechanically for several hours, in order to ensure a uniform distribution of the monomer and the crosslinking agent over the sample volume, before they were cast in small flat sample holders made of Teflon. The samples were exposed under nitrogen atmosphere to a static UV lamp (Philips TL08) with a maximum emission wavelength at $\lambda=365 \mathrm{~nm}$ and an intensity $I_{0}=1.5 \mathrm{~mW}^{-2}$. The exposure time was fixed at $20 \mathrm{~min}$, although $5 \mathrm{~min}$ were sufficient to achieve complete conversion of the monomer.

Prepolymers swelling study:

Investigations on swelling kinetics were carried out on PHEA and PBuA networks to see the compatibility which exists between the two prepolymers. The influence of the chemical nature of the monomer on the swelling behavior of the networks is examined. For each network, the used solvent is the reactive solution containing the other (Monomer/ Crosslinker/ Photoinitiator). Swelling behavior in terms of the swelling ratio $Q$ in the case of an usual solvent is given as:

Swelling ratio $=\mathrm{Q}=\left(\frac{W_{\mathrm{S}}-W_{i}}{W_{i}}\right) \times 100$

Where $W_{s}$ is the weight of the swollen network and $W_{i}$ is the weight of initially dried network. 


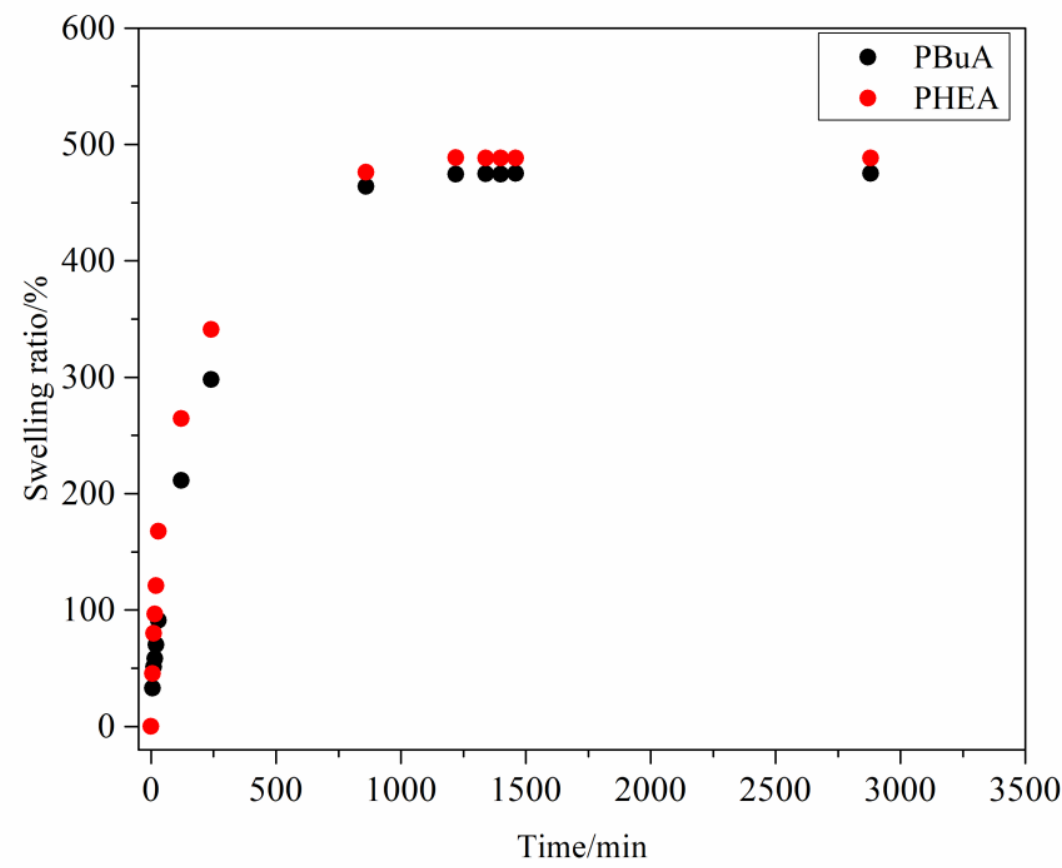

Fig. 1 Swelling of the polymer networks in the reactive solution containing the monomers

This figure constitutes a measure of the quantity of the reactive solution absorbed by the two different polymer networks. As the time proceeds, the two reactive solutions diffúse into the networks due to the concentration gradient resulting in the exponential swelling of the network. From the same swelling curve, it's observed that the two polymer networks have, practically, a similar physical behavior, that is to say they swell both in the same way and the same speed. Indeed, we note that they have almost the same swelling ratio with a slight increase on the side of the PHEA network and this is probably due to the chemical structure of the starting monomer forming the PHEA network which is large (6 carbons) compared to the n-BuA monomer. This means that the PHEA polymer network offers more space for the n-BuA monomer to diffuse in the network than in the opposite case. We can also say that the two polymer networks have maximum swelling ratios (around 475 for the $\mathrm{PBuA}$ network and 488 for the PHEA), which means that each network can swell up to 4.8 times its initial volume. With a small logic, each network contains the equivalent of 3.5 networks in addition to the initial network. In the theoretical part, we took this result into consideration with an approximation that each network contains the equivalent of three polymer networks plus the initial network. We added an intermediate network containing the same number of polymer networks to see the effect of the monomer on the physical behavior of the resulting IPNs.

IPNs synthesis:

Two kinds of sequential IPNs were synthesized. The first one consists of a PBuA network, swollen, until reaching equilibrium, in a solution containing the second monomer (2-HEA)/Crosslinker/Photoinitiator. The swollen sample was then exposed to UV irradiation (the same used before). The exposure time was fixed to 20 min to achieve complete conversion of all monomers in the precursor system. The resulting network will be called Ex-IPN1 (Experimental-IPN1). The second IPN was obtained with the same method described above, 
except that at first a PHEA network was formed, which was swollen in a second step, until reaching equilibrium, by a solution containing $\mathrm{n}-\mathrm{BuA}$, as mentioned before. The resulting network will be called Ex-IPN2.

\section{TG measurement:}

Investigations were made in a Perkin Elmer Pyris TGA instrument while heating the samples from 25 to $700^{\circ} \mathrm{C}$ at the rate of $10^{\circ} \mathrm{C} / \mathrm{min}$ in nitrogen. Samples for thermal measurements were prepared by introducing approximately $10 \mathrm{mg}$ of the sample into a TG pan. At least three duplicate samples having the same composition and prepared independently were used to check the reproducibility of the results. The polymer degradation temperature was determined from the midpoint of the transition range of the curves.

\section{DSC measurement:}

The Differential Scanning Calorimetry (DSC) technique was used for the study of polymer networks materials and in particular to detect the glass transitions temperature $\left(T_{g}\right)$ [54-55]. DSC measurements were performed on a Perkin Elmer Pyris Diamond calorimeter equipped with an Intracooler 2P system allowing cooling experiments. Samples for calorimetric measurements were prepared by introducing approximately $8 \mathrm{mg}$ of the material into an aluminum DSC pan, which was sealed to avoid evaporation effects during the temperature treatment. A rate of $10^{\circ} \mathrm{C} / \mathrm{min}$ (heating and cooling) was used in the temperature range from -75 to $150^{\circ} \mathrm{C}$. The program consists first in cooling the sample followed by three heating and cooling cycles to take into account eventual thermal events related to the sample preparation history. The results presented in this work were obtained from the first heating ramps. In each case, at least three duplicates having the same composition and prepared independently were used to check the reproducibility of results.

\section{Simulation details:}

Simulation software:

The Culgi software (Chemistry Unified Language Interface from culgi.com) is used for the generation of the different systems, for the energy minimization, equilibrating systems and calculating the energy functional forms with the DREIDING Force Field [56]. The different macroscopic (volumetric) and microscopic (structural) properties were done by the LAMMPS software package (Large-scale Atomic Molecular Massively Parallel Simulator from lammps.sandia.gov) and the results obtained from the latter are visualized and interpreted by the VMD software University of Illinois (http://www.ks.uiuc.edu/Research/vmd/) [57-58].

\section{Simulation procedure:}

The methodology followed for the elaboration of the two Acrylate-based networks PBuA and PHEA and this in order to lead to the synthesis of sequential IPN networks is detailed. All the simulations have been carried out using DREIDING force-field [59-60] who is a simple, generic all-atom force field, developed by Mayo and coworkers at BioDesign Incorporated. DREIDING FF was developed to predict structures and dynamics of organic, biological, and main-group inorganic molecules. The generated structures with the builder included with the CULGI software do not exactly represent the equilibrate state of the system. Although excluded volume effects are taken into account, a certain degree of overlap still exists in the generated structures. Since the amount of interatomic overlap in the system depends on the density of the system, it is recommended to perform an energy minimization calculation followed by a few steps of molecular dynamics simulation with a very small time step on the structure to minimize this overlap, and the resulting high-energy hot spots in the structure, 
before any further simulation attempted [60]. For the final structures, minimization is carried out to reach the lowest energy state, and the MD simulation procedure was performed. The MD simulation follows the algorithm given in the Fig. 2. All systems were equilibrated for $100 \mathrm{ps}$ with $0.1 \mathrm{fs}$ time steps at $\left(\mathrm{T}=298{ }^{\circ} \mathrm{K}\right.$, and $\mathrm{P}=1 \mathrm{bar}$ for NPT ensemble) with a frame output every 500 steps. The Berendsen thermostat and barostat [61] were used to maintain the temperature and pressure for all NVT and NPT simulations. Firstly, an NVT-MD simulation was performed to release any possible tensions. Secondly, an NPT-MD simulation is performed to bring the system back to experimental density. This protocol prevents the superimposition of segments or the formation of loops in the case of dense polymers. Finally, the simulation was carried out until the density of each system was stabilized. The non-bonded van der Waals and electrostatic interactions were truncated using atom based cut off distance of $12.5 \mathrm{~A}^{\circ}$. Periodic boundary conditions were implemented in all three principal directions.

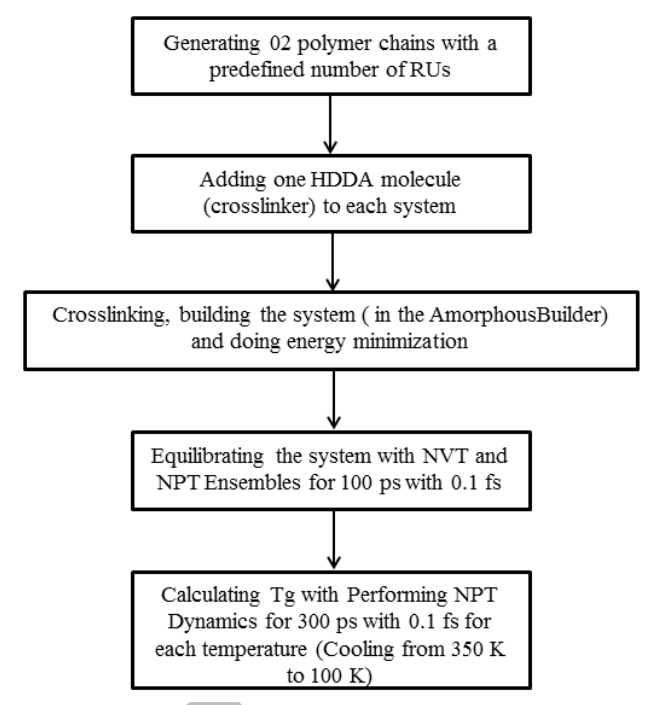

Fig. 2 Summary of our process to equilibrate the different systems

\section{Generating prepolymer networks:}

There are four points for generating the initial configurations of each polymer network. Initially, the polymeric repeat unit $(\mathrm{RU})$ must be created and minimized (See Fig. 3). Then, this repetitive unit is used to generate a defined length polymer chain (160 RUs for PBuA and 130 for PHEA in our case). This latter is relaxed, in order to obtain the most stable configuration. The third phase consists in inserting the relaxed polymer chains together with one molecule of the crosslinker HDDA in a periodic homogeneous box with dimensions $30 \times 30 \times 30 \mathrm{~A}^{\circ}$. For the studied polymer networks, the confinement was carried out relative to the experimental approach. Finally, the last step is to create bonds between the two polymer chain and the crosslinker in the box.

\section{Generating interpenetrating polymer networks:}

The creation of interpenetrating polymer networks is based on the main definition of these latters. The definition of sequenced synthesis stipulates that a network is synthesized in the immediate presence of the other one. That is, a network is created knowing that the first already exists. Given the complexity of the model, we have established an approximation based on the simple addition of polymer networks together in a simulation cube with different proportions to try to be as close as possible to the experiment and then we built the IPNs in the AmorphousBuilder module of the CULGI Software (See Fig. 4). The polymer networks were interpenetrated with each other due to the formation of physical entanglements between them without covalent bonds. 
We constructed three types of sequential IPNs by varying the amount of the second polymer network. T-IPN1 (Theoretical-IPN1) contains in its structure the quantity of one PBuA network to which is added the quantity of three PHEA networks. T-IPN2 contains one PHEA network with three PBuA network and finally T-IPN3 contains the same amount of polymer networks, that is to say a PBuA network with another one of PHEA which makes the proportion 50/50.

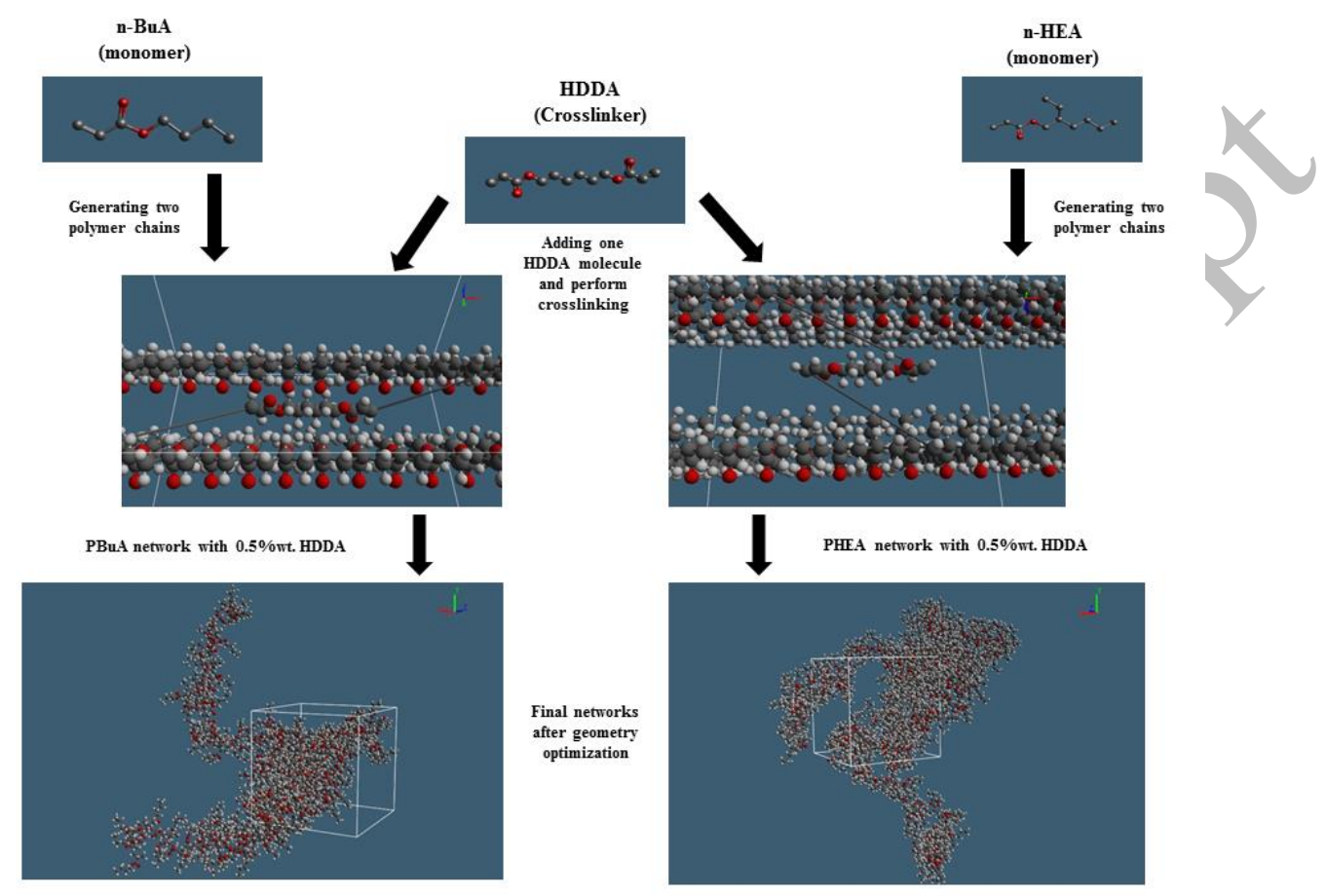

Fig. 3 Chemical structure of the RUs and generating polymer (Grey-carbon; Red-oxygen; White-hydrogen)

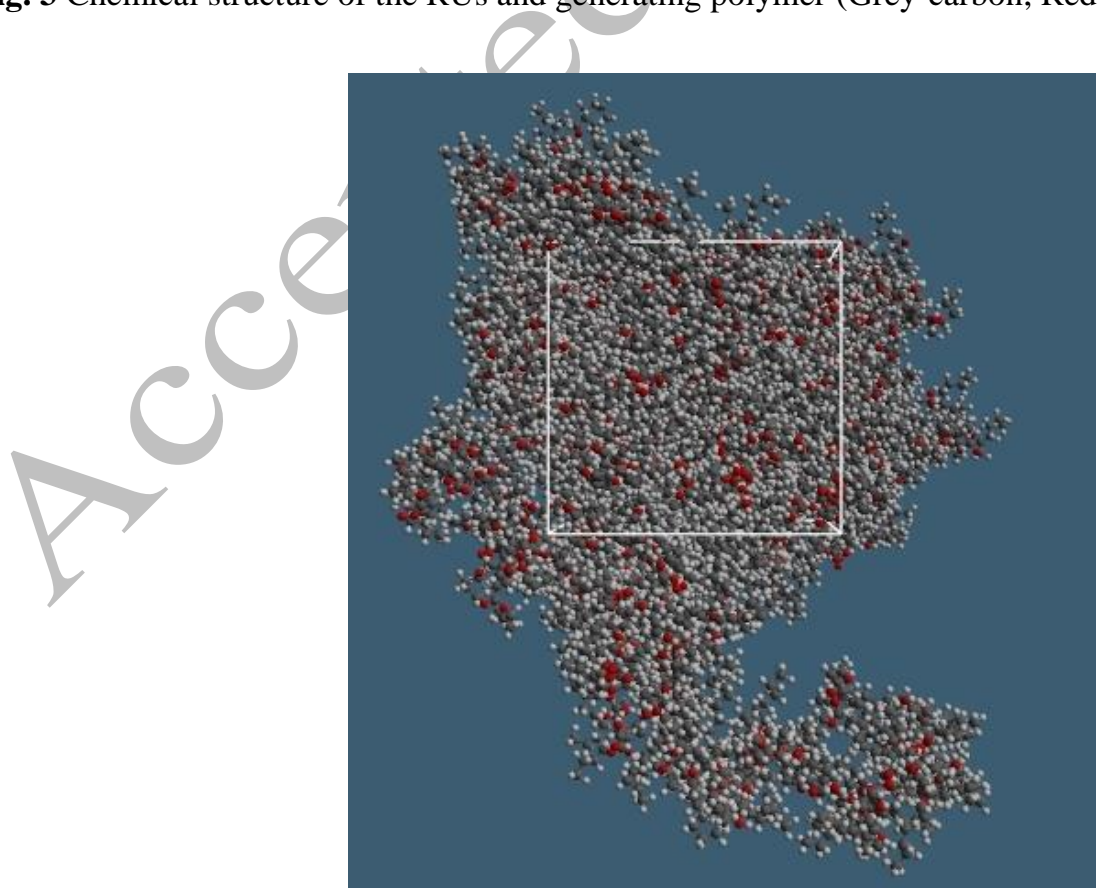

Fig. 4 Snapshots of the T-IPN1 built with the AmourphousBuilder 


\section{Functional forms with the DREIDING FF:}

In a molecular model, a force field defines interactions between atoms. A force field is determined by the functional form of the different interatomic interactions, and by the parameters used for these interactions. The DREIDING force field use functional forms that are given below [59-60]. Energies are generally expressed in $\mathrm{Kcal} \mathrm{mol}^{-1}$, lengths and distances in angstrom, angles in degrees (but angle force constants use radians instead of degrees). Units of force field parameters follow from this and the specific functional forms, but for completeness they are also given below.

\section{Bond stretching}

The bond stretching harmonic potential is given by:

$u_{r}=k_{r}\left(r-r_{0}\right)^{2}$

where $\mathrm{r}_{0}$ is the equilibrium bond length expressed in angstrom and the bond stretching constant $\mathrm{k}_{\mathrm{r}}$ is expressed in kcal mol ${ }^{-1}{ }^{\circ} \mathrm{A}^{-2}$.

\section{Angle bending}

The angle bending harmonic potential is given by:

$u_{\theta}=k_{\theta}\left(\theta-\theta_{0}\right)^{2}$

where $\theta_{0}$ is the equilibrium angle expressed in degrees and the angle bending constant $\mathrm{k}_{\theta}$ is expressed in kcal $\mathrm{mol}^{-1} \mathrm{rad}^{-2}$.

Angle bending potential in cosine form:

$u_{\theta}=k_{\theta}\left(1-\cos \left(\theta-\theta_{0}\right)\right)$

Here, the angle bending constant has units of $\mathrm{kcal} \mathrm{mol}^{-1}$

Angle bending potential in cosine form (DREIDING style):

For $\theta \neq 180^{\circ}$

$u_{\theta}=\frac{1}{2} C_{\theta}\left(\cos \theta-\cos \theta_{0}\right)^{2}$

For $\theta=180^{\circ}$

$u_{\theta}=K_{\theta}(1+\cos \theta)$

where $\theta_{0}$ is the equilibrium angle and

$C_{\theta}=\frac{K_{\theta}}{\left(\sin \theta_{0}\right)^{2}}$

The angle bending constant has units of $\mathrm{kcal} / \mathrm{mol}$.

\section{Torsion}

Cosine series for torsional potential:

$u_{\phi}=V_{0}+V_{1}(1+\cos \phi)+V_{2}(1-\cos 2 \phi)+V_{3}(1+\cos 3 \phi)$

The force constants $V_{0}, V_{1}, V_{2}, V_{3}$ have units of kcal mol${ }^{-1}$.

Torsional potential in cosine form (DREIDING style):

$u_{\theta}=\frac{1}{2} V_{0}\left[1-\cos n\left(\phi-\phi_{0}\right)\right]$

where $\mathrm{n}$ and $\Phi_{0}$ determine the equilibrium angles. The force constant $\mathrm{V}_{0}$ has units of $\mathrm{kcal} / \mathrm{mol}$.

\section{Inversion}

Inversion potential for planar configurations in cosine form (DREIDING style):

$u_{\psi}=K_{\psi}(1-\cos \psi)$

The inversion constant $u_{\psi}$ is expressed in $\mathrm{kcal} \mathrm{mol}^{-1}$. 


\section{Van der Waals interactions}

Lennard-Jones 12-6:2: The equation for an alternate form of the Lennard-Jones 12-6 potential, used by DREIDING, is given below:

$u\left(r_{i j}\right)=\epsilon_{i j}\left[\left(\frac{\sigma_{i j}}{r_{i j}}\right)^{12}-2\left(\frac{\sigma_{i j}}{r_{i j}}\right)^{6}\right]$

where $\mathrm{r}_{\mathrm{ij}}, \epsilon_{\mathrm{ij}}$, and $\sigma_{\mathrm{ij}}$ denote the distance between the interacting sites, the Lennard-Jones well depth and the size parameter, respectively, for the pair of atoms $\mathrm{i}$ and $\mathrm{j}$.

Here, $\mathrm{r}_{\mathrm{ij}}$ and $\sigma_{\mathrm{ij}}$ are both expressed in A so that the constant $\epsilon_{\mathrm{ij}}$ has units of kcal mol ${ }^{-1}$.

For interaction parameters between unlike pairs, the geometric combination rule for $\epsilon_{\mathrm{ij}}$ is given:

$\epsilon_{i j}=\left(\epsilon_{i i} \epsilon_{j j}\right)^{1 / 2}$

For $\sigma_{\mathrm{ij}}$, the arithmetic and geometric combination rules are given by:

- The arithmetic combining rule

$\sigma_{i j}=\frac{1}{2}\left(\sigma_{i i}+\sigma_{j j}\right)$

- The geometric combining rule

$\sigma_{i j}=\left(\sigma_{i i} \sigma_{j j}\right)^{1 / 2}$

\section{The radial distribution function:}

The Radial Distribution Function (RDF) measures the probability of finding a particle at distance $r$ given that there is a particle at position 0 . For small distances, the radial distribution is closely related to the packing of the molecules. Since at close distances the interatomic interactions are quite hard in nature, the distribution function shows a structure with regular peaks. At long distances, the layers become diffuse, and thus the probability of finding two atoms with a given separation is essentially a constant and proportional to the density. The RDF, denoted as $g(r)$, is normalized by the density to provide a limit in $g$ value of 1 at large values of $r$. There are two main types of RDF. One is that of a collection of atoms with itself (for example, just taking all atoms in a particular system) and the other is the RDF for atoms from two disjoint collections (for example, the RDF of a particular atom in one type of molecule with a particular atom in another type of molecule). The expression used to calculate the radial distribution function for (arbitrary) collections A and B is given by

$g(r)=\frac{V}{N_{a b}^{\text {total }}} \frac{N_{a b}\left(r-\frac{1}{2} \Delta r, r+\frac{1}{2} \Delta r\right)}{\frac{4}{3} \pi\left[\left(r+\frac{1}{2} \Delta r\right)^{3}-\left(r-\frac{1}{2} \Delta r\right)^{3}\right]}$

Where $\mathrm{V}$ is the total volume of the system, $N_{a b}^{\text {total }}$ is the total number of pairs consisting of one bead from collection $\mathrm{A}$ and one from collection $\mathrm{B}$, and $N_{a b}\left(r-\frac{1}{2} \Delta r, r+\frac{1}{2} \Delta r\right)$ is the number of $\mathrm{AB}$ atom pairs with distance between $r-\frac{1}{2} \Delta r$ and $r+\frac{1}{2} \Delta r$ (so with displacement vector with in a spherical shell with thickness $\Delta \mathrm{r}$ around distance $\mathrm{r}$ ). The expression in the second denominator is the volume of such a shell.

For the shell volume, the approximate expression $4 \pi r^{2} \Delta r$ can be used and then simplify the expression by defining $N_{a b}\left(r-\frac{1}{2} \Delta r, r+\frac{1}{2} \Delta r\right)$. For the case where collection $\mathrm{A}$ is identical to collection $\mathrm{B}$, the number of pairs becomes $\frac{1}{2} N(N-1)$, with $\mathrm{N}$ the number of beads in the collection. We then obtain the more familiar expression

$g(r)=\frac{2 V}{N(N-1)} \frac{n(r)}{4 \pi r^{2} \delta r}$ 


\section{Results and discussions:}

\section{TG Results:}

The curve corresponding to TG and DTG analysis are given in Fig. 5-a and Fig. 5-b respectively. The corresponding data are given in table 1. The inset of this figures shows the same results based on the range between 350 and $470{ }^{\circ} \mathrm{C}$. It can be observed from our study that all the polymer networks have almost the same thermal behavior. Indeed, all the studied networks are stable up to $300{ }^{\circ} \mathrm{C}$; a continuous mass loss in the range $\left(340-460{ }^{\circ} \mathrm{C}\right.$ ) characterized by an important mass loss, and decomposes completely beyond $550{ }^{\circ} \mathrm{C}$. The corresponding phenomena could be interpreted by a complete degradation of the materials (mass loss: 99.61\%). All products decompose in a single step. The kinetic aspect of the degradation depends on the compound of networks; Indeed, The Ex-IPN1 has a degradation kinetic similar to the one of PHEA network, and the Ex-IPN2 has a degradation kinetic similar to the one of PBuA network. From the DTG curve (Fig. 5-b) we can see that the peaks of the curves presented for the simple polymer networks are slightly wide in comparison to those presented by IPNs; this is probably due to the presence of some unreacted oligomers with the networks structure forming thereby an isolated blocks of polymer chains from the polymer network. These blocks begin to detach and degrade first by increasing the temperature followed by the skeleton of the sample. This behavior is less existed by increasing the density of the network leading us to the formation of IPNs, which confirms that we have stable IPNs in their structures by comparing them to the starting products.
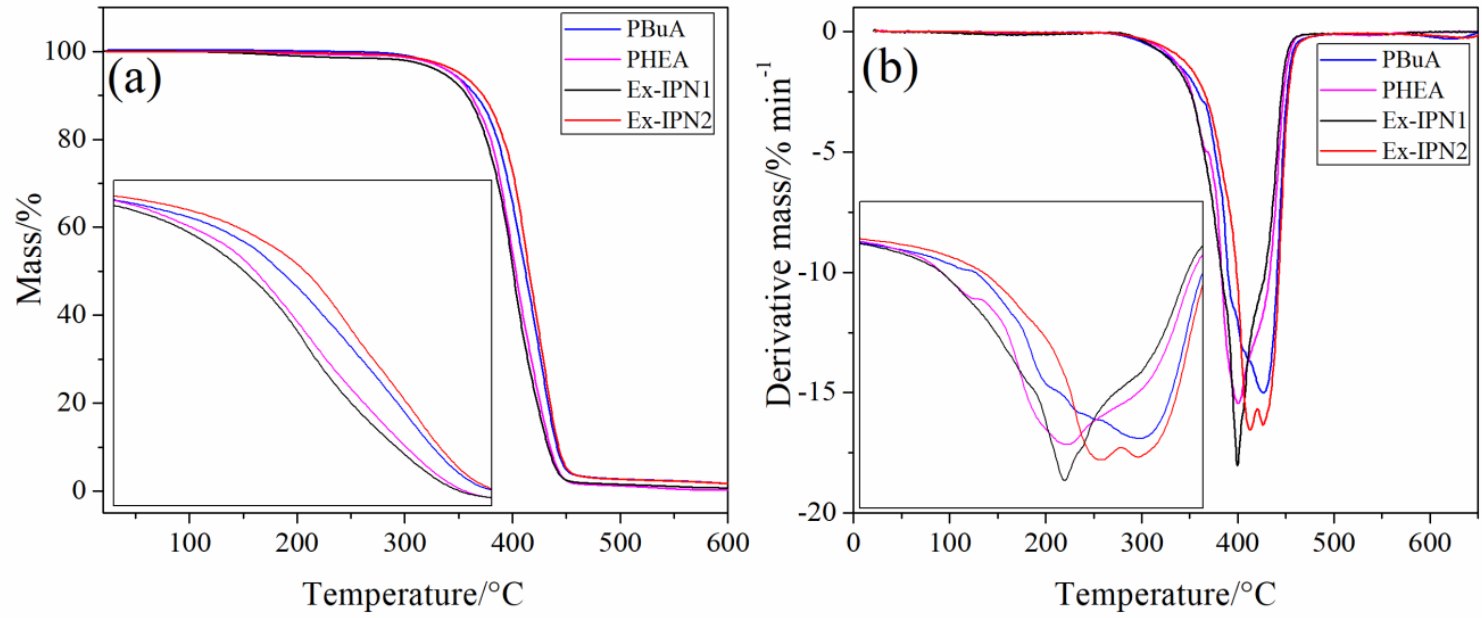

Fig. 5 TG (a) and DTG (b) Curves for the different Polymer networks

Table 1 Degradation Data of the different polymer networks

\begin{tabular}{llll}
\hline \hline & $T_{5 \%} /{ }^{\circ} \mathrm{C}$ & $T_{50 \%} /{ }^{\circ} \mathrm{C}$ & $T_{95 \%} /{ }^{\circ} \mathrm{C}$ \\
\hline Ex-IPN1 & 328 & 400 & 438 \\
\hline Ex-IPN2 & 344 & 414 & 448 \\
\hline PBuA & 344 & 411 & 449 \\
\hline PHEA & 344 & 402 & 442 \\
\hline \hline
\end{tabular}

The thermal stabilities of the different polymer networks were evaluated from TG results checking temperature corresponding to $5 \%, 50 \%$, and $95 \%$ of mass loss $\left(\mathrm{T}_{5 \%}, \mathrm{~T}_{50 \%}\right.$, and $\left.\mathrm{T}_{95 \%}\right)$. The start of degradation for all samples appeared to begin, with a light difference, at around the same temperature. After $50 \%$ of mass loss, the thermal behavior for the IPNs is found to be influenced by the nature of their precursory networks. Indeed, The Ex-IPN1 
has a degradation behavior similar to the one of PHEA network, and the Ex-IPN2 has a degradation behavior similar to the PBuA network. This behavior continues until the last stage of total degradation.

\section{DSC results:}

The Thermal Analysis was carried out to know the phase separation behavior that can exist in the different polymer networks. Three samples from each system were studied. Once the results obtained, it is possible to draw the tangents to the curve of the heat flow and the glass transition temperature of the polymer was determined from the Half $\mathrm{C}_{\mathrm{p}}$ Extrapolated point of the transition range of the curves. For the analysis of the DSC, the study focused on the first heating, that is to say the first cycle of temperature variation $\left(-70^{\circ} \mathrm{C}\right.$ to $120^{\circ} \mathrm{C}$ ). Having obtained similar curves for the three tests, we presented only one curve for each composition. Fig. 6 represents the glass transition temperatures variation of the different networks. Only one single transition in the DSC curves for all the polymers is detected, especially for the two synthesized IPNs which indicates that the IPNs does not present phase separation. This would suggest that the different monomer 2-HEA and $n-B u A$ are perfectly miscible. In addition, these figures informs us that the glass transition temperatures of both IPNs are close from/to each other and are controlled first by the quantity of the precursory polymer network present in the mixture. Indeed, the $\mathrm{T}_{\mathrm{g}}$ of the Ex-IPN1 shows a slight shift compared with the $\mathrm{T}_{\mathrm{g}}$ of the PHEA network. Apparently with the presence of the PBuA in the Ex-IPN1 structure, this decreasing of $\mathrm{T}_{\mathrm{g}}$ was expected because in the network IPN1 where the presence of the monomer 2-HEA is governing, this last tends to influence its behavior and thus to have glass transition temperature more or less close to that of the pure network PHEA, and vice-versa.

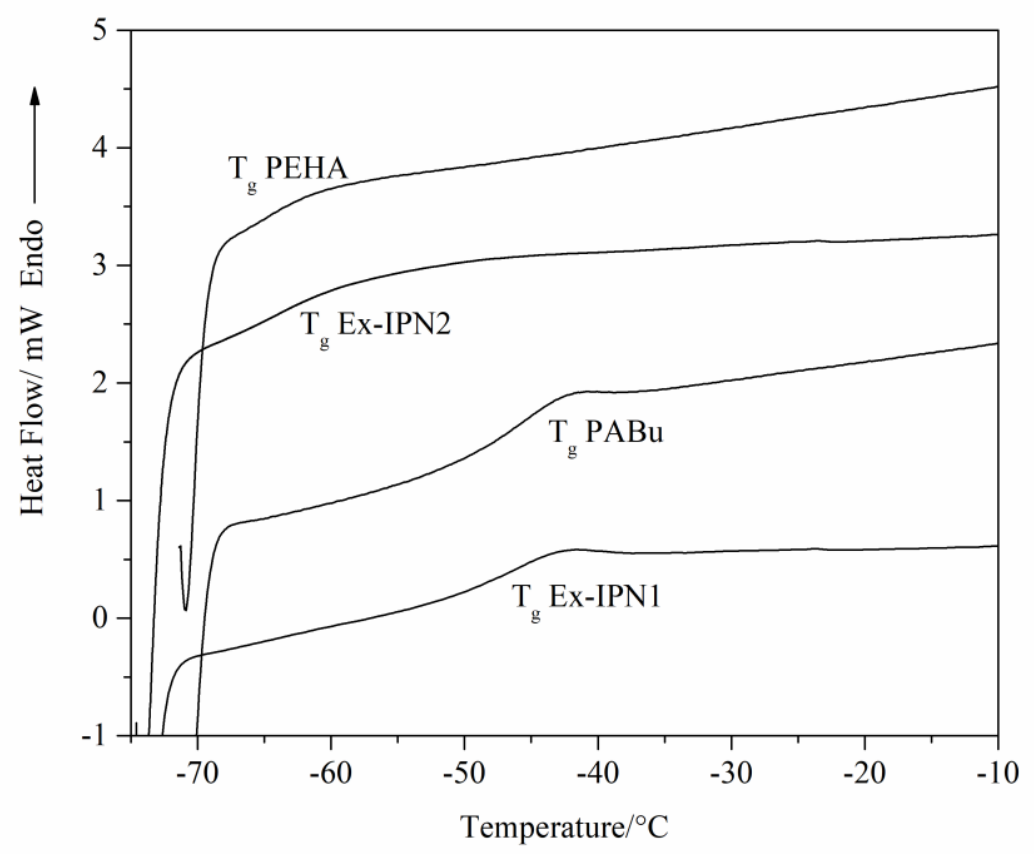

Fig. 6 Experimental DSC Curves of the different systems at a heating rate of $10^{\circ} \mathrm{C} \mathrm{min}^{-1}$ 


\section{Atomistic simulation:}

The generated atomistic structures have very high energies and cannot be served directly as starting configurations for molecular dynamics simulation. The minimization of a molecular model having a big size (number of atoms 36000) can converge towards a global minimum. But, to confirm this minimum reached, several minimizations must be made, starting from different initial conformations. The QM minimization method proposed by D. Sheppard et al. [62] is employed to obtain the minimized structures. The principle idea of this method is to follow the force vector from an initial configuration to a stationary point of energy, while accelerating the system in the direction of the force (which mimics the actual dynamics). In addition to this acceleration, some depreciation is necessary to stop at the local minimum. This is usually done through a proportional and speed-dependent 'force' of damping. In QM mode, this damping procedure is replaced by a projection of the velocity along the force. The QM method can be coupled to a molecular dynamics integrator; Euler integrator in this case [60]. The initial values of the potential energy of the different samples by DREIDING force field are Ep $=1.54 \mathrm{E}+07 \mathrm{kcal} \mathrm{mol}^{-1}, \mathrm{Ep}=3.18793 \mathrm{e}+07 \mathrm{kcal} \mathrm{mol}^{-1}$, and Ep $=1.57867 \mathrm{e}+07 \mathrm{kcal}$ $\mathrm{mol}^{-1}$ for the T-IPN1, T-IPN2 and T-IPN3 respectively. After performing the minimization process, the systems start to reduce its energies gradually according to the number of iterations until they reach a stable minimum energy (Table 2). The new values of the minimum energy are: Ep $=65066.001 \mathrm{kcal} \mathrm{mol}^{-1}$ after 8050 steps for TIPN1, Ep $=5.95389 \mathrm{e}+04 \mathrm{kcal} \mathrm{mol}^{-1}$ after 1034 steps for T-IPN2 and Ep $=269226 \mathrm{kcal} \mathrm{mol}^{-1}$ after 2688 steps for T-IPN3.

Table 2 minimization results of the different samples with QM method

\begin{tabular}{cccccccc}
\hline \hline \multirow{2}{*}{ Polymer } & $\begin{array}{c}\text { Bond } \\
\text { Stretching } \\
/ \mathrm{kcal} \mathrm{mol}^{-1}\end{array}$ & $\begin{array}{c}\text { Angle } \\
\text { Bending } \\
/ \mathrm{kcal} \mathrm{mol}^{-1}\end{array}$ & $\begin{array}{c}\text { Torsion } \\
/ \mathrm{kcal}^{-1} \\
\mathrm{~mol}^{-1}\end{array}$ & $\begin{array}{c}\text { Inversion/ } \\
\mathrm{kcal} \mathrm{mol}^{-1}\end{array}$ & $\begin{array}{c}\text { VdW } \\
/ \mathrm{kcal} \mathrm{mol}^{-1}\end{array}$ & $\begin{array}{c}\text { Total } \\
\text { Potential/ } \\
\mathrm{kcal} \mathrm{mol}^{-1}\end{array}$ \\
\hline \hline \multirow{2}{*}{ T-IPN1 } & Initial & 3813.90 & 4276 & 1391.67 & 87.12 & $4.41484 \mathrm{e}+07$ & $1.54 \mathrm{e}+07$ \\
\cline { 2 - 8 } T-IPN2 & Final & 1710208.5 & 514967.4 & 2920.83 & 6911.72 & $7.82499^{\mathrm{e}}+06$ & $6.5066 \mathrm{e}+04$ \\
\cline { 2 - 8 } & Final & $1.16478 \mathrm{e}+06$ & 381818 & 2460.4 & 9256.82 & $4.39558 \mathrm{e}+06$ & $5.95389 \mathrm{e}+04$ \\
\hline \hline \multirow{2}{*}{ T_IPN3 } & Initial & 3463.46 & 3923.68 & 1302.32 & 98.8054 & $1.57779 \mathrm{e}+07$ & $1.57867 \mathrm{e}+07$ \\
\cline { 2 - 8 } & Final & 34449.9 & 55967.6 & 2626.71 & 812.579 & 175369 & 269226 \\
\hline \hline
\end{tabular}

\section{Thermal results:}

Volumetric properties (Dilatometry technique):

One of the most popular theoretically approaches used to evaluate the compatibility between polymers is the glass transition temperature $\mathrm{T}_{\mathrm{g}}$ determination of the studied system and compare it with the experimental values of the component polymers. This theoretical one remains dependent on the chosen cooling rate for the simulation. Metalta and Soldera [63-64] showed this effect by performing simulations on different polymer systems and found that the agreement between the two glass transitions, experimental and theoretical, is more improved at low cooling rates. It is evident that if these low cooling speeds lead to a better prediction, they lead to too long computational times. In our case, the theoretical measurements of the glass transition temperature for the different systems were performed step by step for each temperature by doing a cooling from $350{ }^{\circ} \mathrm{K}$ to 100 ${ }^{\circ} \mathrm{K}$ by increments of $25^{\circ} \mathrm{K}$. At each temperature, the constant NPT MD simulation was conducted for 300 ps and 
the conditions were kept the same as descripted in the simulation details section. During this procedure, the specific volume was calculated at each temperature and the glass transition temperature is determined by the intersection of the two slopes of the two curves corresponding to the process of heating and cooling as mentioned in Fig. 7. All the values obtained during this study for all the polymers are gathered in the table 3.

Table $3 \mathrm{~T}_{\mathrm{g}}$ result values of the different systems with two determination methods (All the temperature values are in $\left./{ }^{\circ} \mathrm{C}\right)$

\begin{tabular}{|c|c|c|c|c|c|c|}
\hline & & IPN1 & IPN2 & IPN3 & PBuA & PHEA \\
\hline Exper & mental & -65.24 & -46.68 & -- & -45.25 & -63.07 \\
\hline \multirow{2}{*}{ Theoretical } & Dilatometry & -57 & -35 & -50 & -44 & -58 \\
\hline & $\mathrm{RDF}$ & -56 & -49 & -55 & -45 & -61 \\
\hline
\end{tabular}

As we can realize, although the values of the glass transition temperatures obtained from the proposed model are higher than the experimental values, they remain in good agreement with the latter. This shift in theoretical values is probably due to the cooling rate used during the simulation. It is also to be noted that the addition of a second polymer network in simultaneity with the first structure with various percentages affects the resulting theoretical $\mathrm{T}_{\mathrm{g}}$ and passes the latter closer to that presented by the initial polymer network. Indeed, the $\mathrm{T}_{\mathrm{g}}$ value presented by the T-IPN3 which contains the same proportions of the polymer networks comes between the two values presented by the other T-IPNs which deviate towards the values presented by the predominant networks in the T-IPN. This behavior was observed during the experiment which confirms the good choice of the adopted model during the atomistic simulation.

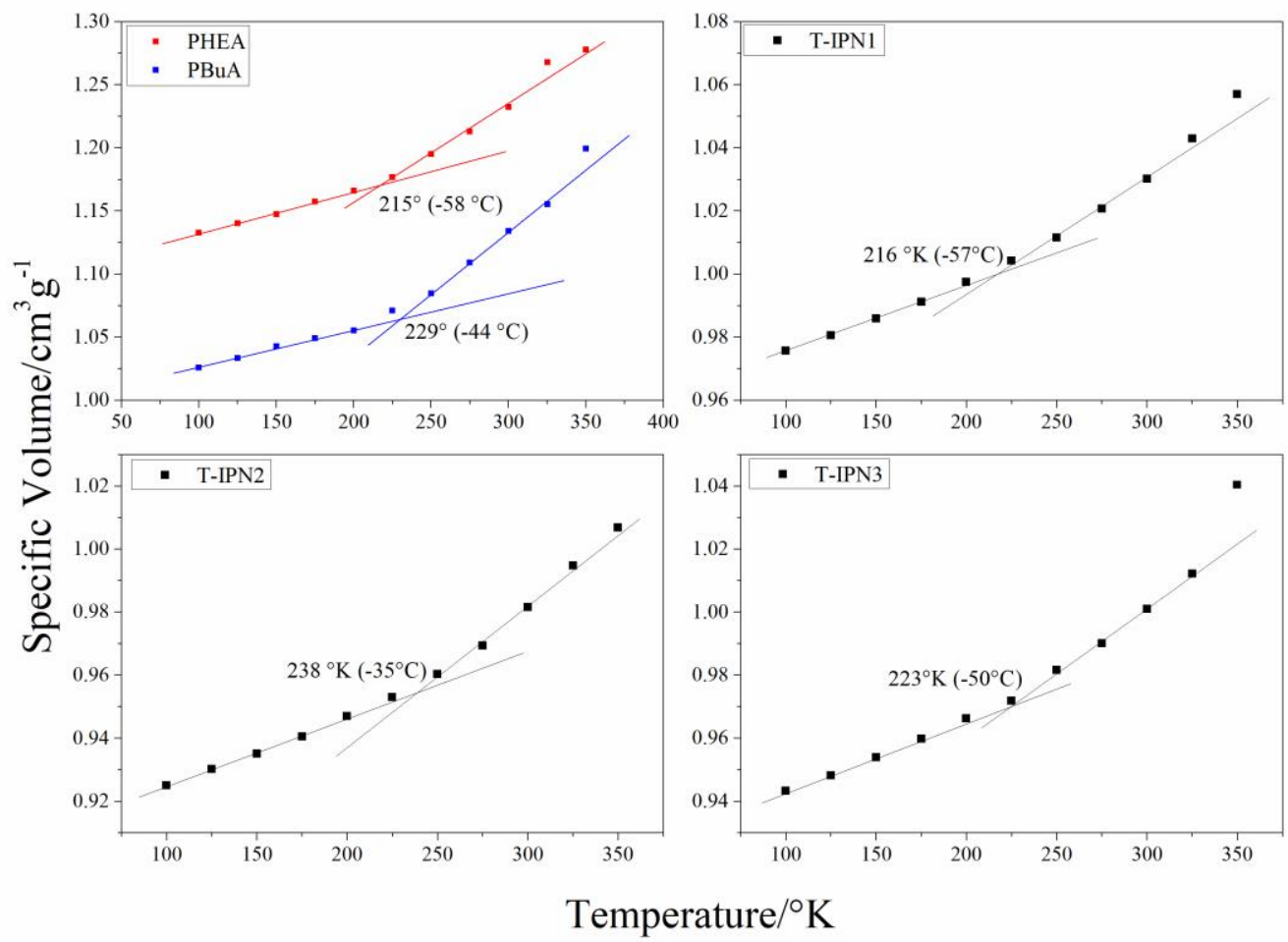

Fig. 7 Evolution of the specific volume according to the temperature for the PHEA, PBuA, T-IPN1, T-IPN2 and T-IPN3 systems 


\section{Structural properties (The radial distribution function):}

The RDF is a concrete option to inspect the structural properties of the polymer systems providing a confirmed approach for the understanding of the atom interactions including the bonding or non-bonding ones. In the Fig. 8 , we present the calculated RDF for the different systems used over this simulation and the inset of these figures shows the same results based on the range between 0.8 and $3.5^{\circ} \mathrm{A}$. We note perfectly that the value of $g(r)$ fluctuates in its values as a function of $\mathrm{r}$. For the different samples the value of $\mathrm{g}(\mathrm{r})$ is usually $>1$ to about $\mathrm{r}=$ $\sim 0.93^{\circ} \mathrm{A}, \sim 1.14<\mathrm{r}>\sim 1.81^{\circ} \mathrm{A}$, and $\sim 2.03<\mathrm{r}>\sim 2.32^{\circ} \mathrm{A}$ before returning to 1 for values of $\mathrm{r}$ greater than 3.13 ${ }^{\circ} \mathrm{A}$. This indicates that the distance to $\mathrm{r}$ between atoms is more frequent than expected for a completely random pattern, suggesting clustering. The values of $g(r)<1$ indicate that the distances between atoms equal to $r$, are less frequent than expected for a completely random process. This suggests regularity. And for $g(r)$ is zero for 0 $<\mathrm{r}>1^{\circ} \mathrm{A}$, this extremely regular configuration has no distance between atoms.

We notice moreover that the intensities of the peaks are temperature dependants. As we can see in insets of the Fig. 8, the different picks presented by the $\mathrm{g}(\mathrm{r})$ curves at $\mathrm{r}=1.1^{\circ} \mathrm{A}$ are greater than the other picks at higher values of $\mathrm{r}$. These later are decreasing in intensity from higher to lower temperatures. This effect looks to be produced by the variations in the density of polymer system with variation of temperature. We we took this effect into consideration and plot in the Fig. 9 the slope of the fitted lines to $\mathrm{g}(\mathrm{r})$ values at $\mathrm{r}=1.1^{\circ} \mathrm{A}$. As is shown, the slopes of the fits lines are crossed around a temperature estimated to be the $\mathrm{T}_{\mathrm{g}}$. The values are presented in table 3 and they stay in good agreement with the experimental one. It should be mentioned is that $T_{g}$ values obtained from structural calculations (RDF) are more accurate and reflect the experiment more better than the calculations obtained by the dilatometry technique.

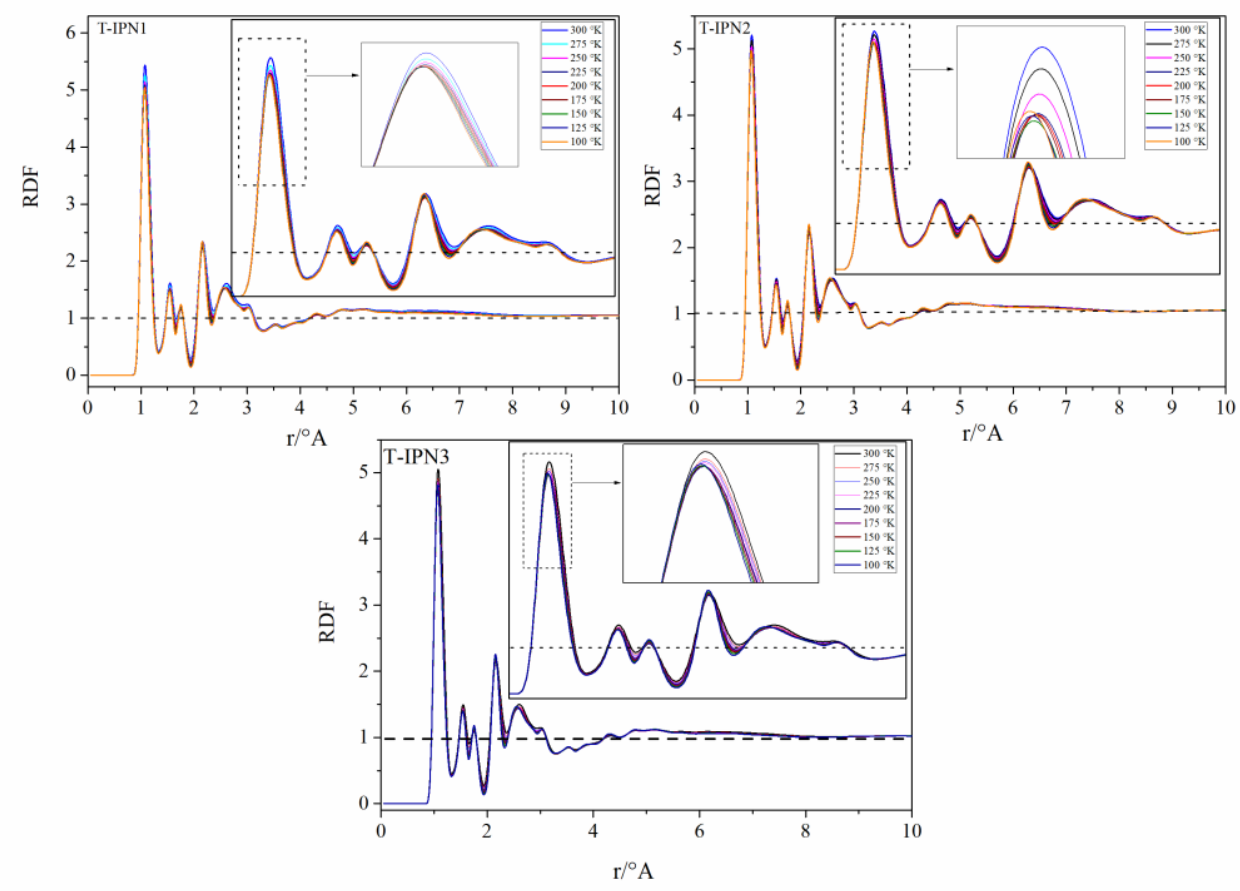

Fig. 8 The radial distribution function for various pairs of atoms for the T-IPN1, T-IPN2 and T-IPN3 systems 


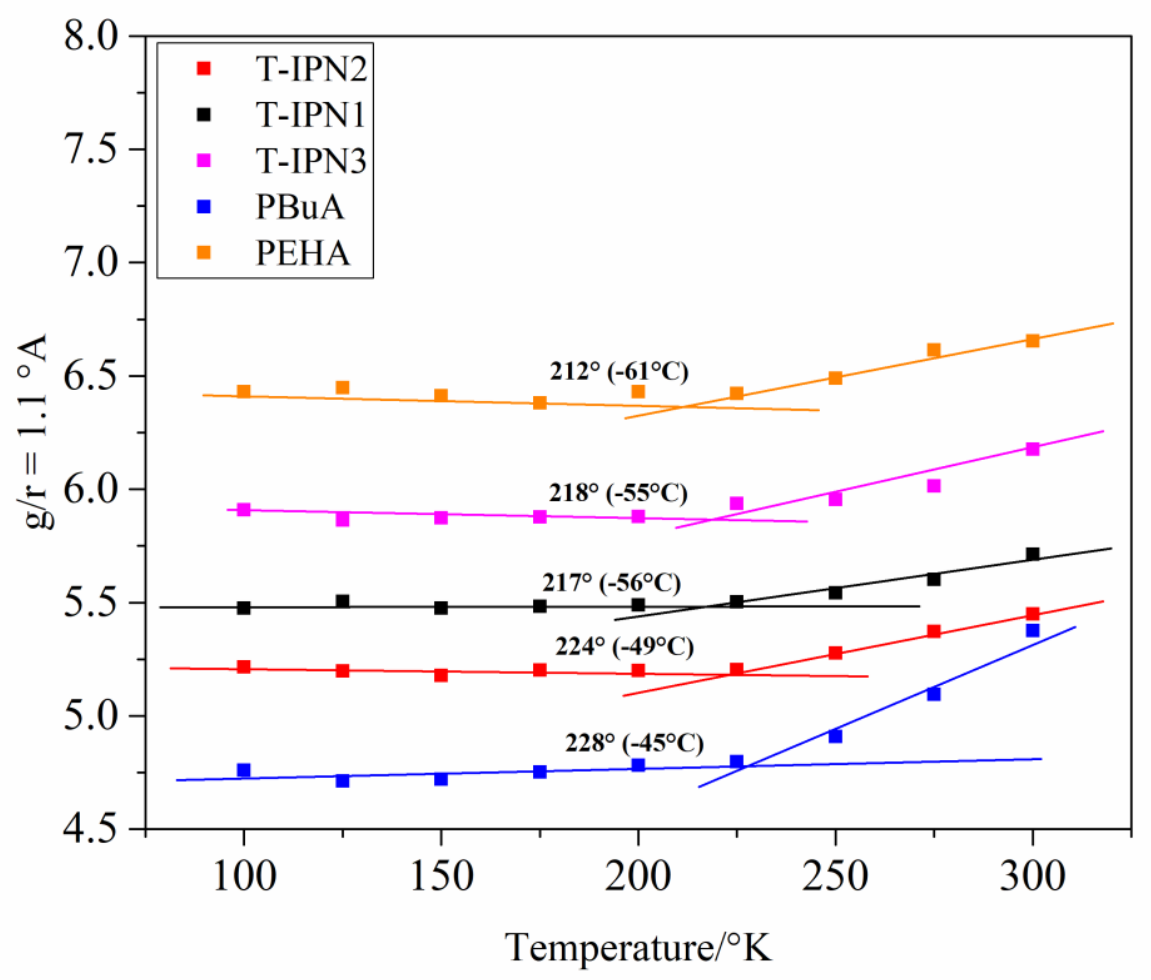

Fig. 9 Evolution of the $\mathrm{g}(\mathrm{r})$ values at $\mathrm{r}=1.1^{\circ} \mathrm{A}$ according to the temperature for the different systems

\section{Conclusion:}

Molecular dynamic models can be used to predict the detailed structure of individual molecules or of very small portions of a larger structure, over a very short period of time (from a few picoseconds up to nanoseconds). In this work we consider two, different but complementary, approaches to characterize the thermophysical behavior of interpenetrating polymer networks, the experimental one in which we present the different techniques used to determine the different parameters governing the interactions between these systems, and another theoretical aim to model these interactions through molecular dynamics simulations. We synthesize a novel sequential interpenetrating polymer network, composed of poly(2-hexyl-ethylacrylate) and poly(n-butyl acrylate) by sequential polymerization technique. The investigated systems are prepared via photo-polymerization by UVcuring of monomers in the presence of a difunctional crosslinker and a photo-initiator. The IPNs properties have been improved by varying the initial composition and the physical properties are investigated by means of TG and DSC techniques. The TG results show that all the networks decompose completely in a single step beyond $550^{\circ} \mathrm{C}$ and the kinetic aspect of the degradation depends on the compound of networks. It was found an increase in the thermal stability with the increase of the density of the polymer network that is, passing from the simple network to the interpenetrating network. The DSC results inform us that the glass transition temperature of the different studied systems is influenced by the amount of the monomers absorbed by the network and that all the resulted IPNs does not present any phase separation. This work is supported by applying molecular dynamics simulation methods (free volume and radial distribution function) to investigate the properties of these polymer networks and effects of composition ratios and temperature. A new approach for the generation and property evaluation of interpenetrating polymer networks is implemented to be close as possible to experiments. The 
different simulation results presented for the volumetric and the structural properties demonstrates that the $\mathrm{T}_{\mathrm{g}}$ values were in good agreement with experimental values. Indeed, the theoretical $T_{g}$ values confirm that each IPN network synthesized is influenced mainly, in its properties, by the amount of the absorbed monomer until reaching equilibrium. Good agreement between Molecular Dynamics simulations and the experimental results indicates the validity of the chosen model.

\section{References:}

1- $\mathrm{Wu}, \mathrm{C}, \& \mathrm{Xu}, \mathrm{W}$. Atomistic molecular modelling of crosslinked epoxy resin. Polymer 2006; http://doi.org/10.1016/j.polymer.2006.06.025

2- Cao, G. Atomistic studies of mechanical properties of graphene. Polymers 2014; http://doi.org/10.3390/polym6092404

3- Fredrickson, GH. The theory of polymer dynamics. Current Opinion in Solid State and Materials Science 1996; http://doi.org/10.1016/S1359-0286(96)80106-9

4- Nieminen, RM. From atomistic simulation towards multiscale modelling of materials. Journal of Physics Condensed Matter 2002; http://doi.org/10.1088/0953-8984/14/11/306

5- Vvedensky, DD. Multiscale modelling of nanostructures. Journal of Physics: Condensed Matter 2004; http://doi.org/10.1088/0953-8984/16/50/r01

6- Holzapfel, GA., \& Ogden, RW. Constitutive modelling of arteriés. In Proceedings of the Royal Society A: Mathematical, Physical and Engineering Sciences 2010; http://doi.org/10.1098/rspa.2010.0058

7- Al Salhi, MS, Alam, J, Dass, LA, \& Raja, M. Recent advances in conjugated polymers for light emitting devices. International Journal of Molecular Sciences 2011; http://doi.org/10.3390/ijms12032036

8- Chodera, JD, \& Noé, F. Markov state models of biomolecular conformational dynamics. Current Opinion in Structural Biology 2014; http://doi.org/10.1016/j.sbi.2014.04.002

9- Baghel, S, Cathcart, H, \& O’Reilly, NJ. Polymeric Amorphous Solid Dispersions: A Review of Amorphization, Crystallization, Stabilization, Solid-State Characterization, and Aqueous Solubilization of Biopharmaceutical Classification System Class II Drugs. Journal of Pharmaceutical Sciences 2016; http://doi.org/10.1016/j.xphs.2015.10.008

10- Gooneie, A, Schuschnigg, S, \& Holzer, C. A review of multiscale computational methods in polymeric materials. Polymers 2017; http://doi.org/10.3390/polym9010016

11- Valverde, JR. Molecular Modelling: Principles and Applications. Briefings in Bioinformatics 2006; http://doi.org/10.1093/bib/2.2.199

12- Rapaport, DC, Blumberg, RL, McKay, SR, \& Christian, W. The Art of Molecular Dynamics Simulation. Computers in Physics 2013; http://doi.org/10.1063/1.4822471

13- Eric Paquet and Herna L. Viktor. Computational Methods for Ab Initio Molecular Dynamics. Advances in Chemistry 2018; https://doi.org/10.1155/2018/9839641.

14- Trewin, A. Molecular Modelling for Beginners. Chromatographia 2010; http://doi.org/10.1365/s10337009-1412-5 
15- Jahangirian, M, Eldabi, T, Naseer, A, Stergioulas, LK, \& Young, T. Simulation in manufacturing and business: A review. European Journal of Operational Research 2010; http://doi.org/10.1016/j.ejor.2009.06.004

16- Fredrickson, GH. The theory of polymer dynamics. Current Opinion in Solid State and Materials Science 1996; http://doi.org/10.1016/S1359-0286(96)80106-9

17- Cheng, X, \& Ivanov, I. Molecular dynamics. Methods in Molecular Biology 2012; http://doi.org/10.1007/978-1-62703-050-2_11

18- Li, Y, Abberton, BC, Kröger, M, \& Liu, WK. Challenges in multiscale modeling of polymer dynamics. Polymers 2013; http://doi.org/10.3390/polym5020751

19- Heinecke A, Eckhardt W, Horsch M, Bungartz HJ. Molecular Dynamics Simulation. In: Supercomputing for Molecular Dynamics Simulations. SpringerBriefs in Computer Science. Springer, Cham 2015; http://doi.org/10.1007/978-3-319-17148-7_2

20- Raabe G. Molecular Dynamics Simulations. In: Molecular Simulation Studies on Thermophysical Properties. Molecular Modeling and Simulation (Applications and Perspectives). Springer, Singapore 2017; https://doi.org/10.1007/978-981-10-3545-6_4

21- Yu, L, Dean, K, \& Li, L. Polymer blends and composites from renewable resources. Progress in Polymer Science 2006; http://doi.org/10.1016/j.progpolymsci.2006.03.002

22- Utracki, LA, \& Wilkie, CA. Polymer blends handbook. Polymer Blends Handbook 2014; http://doi.org/10.1007/978-94-007-6064-6

23- Manias, E, \& Utracki, LA. Thermodynamics of polymer blends. In Polymer Blends Handbook. 2014;http://doi.org/10.1007/978-94-007-6064-6_4

24- Sperling, LH, \& Hu, R. (2014). Interpenetrating polymer networks. In Polymer Blends Handbook. http://doi.org/10.1007/978-94-007-6064-6_8

25- Xu, K, Chen, R, Wang, C. et al. Organomontmorillonite-modified soybean oil-based polyurethane/epoxy resin interpenetrating polymer networks (IPNs). J Therm Anal Calorim 2016; 126 : 1253. https://doi.org/10.1007/s10973-016-5795-x

26- Schiraldi, A. \& Fessas, D.J Therm Anal Calorim 2019; https://doi.org/10.1007/s10973-019-08166-z

27- Ahmadi Khoshooei, M., Fazlollahi, F., Maham, Y. et al. J Therm Anal Calorim 2019; https://doi.org/10.1007/s10973-019-08022-0

28- Łagowska, B, Wacławska, I, Sułowska, J. et al. J Therm Anal Calorim 2019; https://doi.org/10.1007/s10973-019-08446-8/10.1007/s10973-019-08446-8

29- Lipatov YS, Alekseeva TT. Phase-Separated Interpenetrating Polymer Networks. In: Phase-Separated Interpenetrating Polymer Networks. Advances in Polymer Science, vol 208. Springer, Berlin, Heidelberg 2007; http://doi.org/10.1007/12_2007_116

30- Sperling, LH. Interpenetrating Polymer Networks: An Overview 2009; http://doi.org/10.1021/ba-19940239.ch001

31- Shivashankar, M, \& Mandal, BK. A review on interpenetrating polymer network. Int J Pharm Pharm Sci 2012; Vol 4, Suppl 5, 1-7 
32- Matricardi, P, Di Meo, C, Coviello, T, Hennink, WE, \& Alhaique, F. Interpenetrating polymer networks polysaccharide hydrogels for drug delivery and tissue engineering. Advanced Drug Delivery Reviews 2013; http://doi.org/10.1016/j.addr.2013.04.002

33- Dragan, ES. Design and applications of interpenetrating polymer network hydrogels. A review. Chemical Engineering Journal 2014; http://doi.org/10.1016/j.cej.2014.01.065

34- Lohani, A, Singh, G, Bhattacharya, SS, \& Verma, A. Interpenetrating Polymer Networks as Innovative Drug Delivery Systems. Journal of Drug Delivery 2014; http://doi.org/10.1155/2014/583612

35- Ligon-Auer, SC., Schwentenwein, M, Gorsche, C, Stampfl, J, \& Liska, R. Toughening of photo-curable polymer networks: A review. Polymer Chemistry 2016; http://doi.org/10.1039/c5py01631b

36- Feig, VR, Tran, H, Lee, M, \& Bao, Z. Mechanically tunable conductive interpenetrating network hydrogels that mimic the elastic moduli of biological tissue. Nature Communications 2018; http://doi.org/10.1038/s41467-018-05222-4

37- Rao, S, Devi, SNS, Johns, A, Kalkornsurapranee, E, Sham Aan, M, \& Johns, J. Mechanical and thermal properties of carbon black reinforced natural rubber/polyvinyl alcohol fully-interpenetrating polymer networks. Journal of Vinyl and Additive Technology 2018; 24, E21-E29. https://doi.org/10.1002/vnl.21560

38- Kumar, P, Choonara, YE, du Toit, LC, \& Pillay, V. Advances in patented interpenetrating polymeric networks for biomedical applications. Pharmaceutical Patent Analyst 2018; 7(3), 99-101. https://doi.org/10.4155/ppa-2018-0007

39- Sadakbayeva, Z, Dušková-Smrčková, M, Šturcová, A, Pfleger, J, \& Dušek, K. Microstructured poly(2hydroxyethyl methacrylate)/poly(glycerol monomethacrylate) interpenetrating network hydrogels: UVscattering induced accelerated formation and tensile behavior. European Polymer Journal 2018; 101, 304-313. https://doi.org/10.1016/J.EURPOLYMJ.2018.02.035

40- Sen, S, Patil, S, \& Argyropoulos, DS. Thermal properties of lignin in copolymers, blends, and composites: a review. Green Chemistry 2015; 17(11), 4862-4887. https://doi.org/10.1039/C5GC01066G

41- Liu, Z, Zhang, Y, Hu, K, Xiao, Y, Wang, J, Zhou, C, \& Lei, J. Preparation and properties of polyethylene glycol based semi-interpenetrating polymer network as novel form-stable phase change materials for thermal energy storage. Energy and Buildings 2016; 127, 327-336. https://doi.org/10.1016/J.ENBUILD.2016.06.009

42- Zanjanijam, AR, Hakim, S, \& Azizi, H. Rheological, mechanical and thermal properties of the PA/PVB blends and their nanocomposites: Structure-property relationships. Polymer Testing 2018 66, 48-63. https://doi.org/10.1016/J.POLYMERTESTING.2018.01.006

43- Somsunan, R. \& Mainoiy, N. J Therm Anal Calorim 2019; https://doi.org/10.1007/s10973-019-08631-9

44- Baatti, A, Erchiqui, F, Godard, F. et al. J Therm Anal Calorim 2019; https://doi.org/10.1007/s10973019-08497-X

45- Wong, WSY, Stachurski, ZH, Nisbet, DR, \& Tricoli, A. Ultra-Durable and Transparent Self-Cleaning Surfaces by Large-Scale Self-Assembly of Hierarchical Interpenetrated Polymer Networks. ACS Applied Materials \& Interfaces 2016; 8(21), 13615-13623. https://doi.org/10.1021/acsami.6b03414 
46- Zhong, C, Ke, D, Wang, L, Lu, Y, \& Wang, L. Bioactive interpenetrating polymer networks for improving the electrode/neural-tissue interface. Electrochemistry Communications 2017 79, 59-62. https://doi.org/10.1016/J.ELECOM.2017.04.015

47- Park, SR., Kang, JH, Ahn, DA, \& Suh, MC. A cross-linkable hole transport material having improved mobility through a semi-interpenetrating polymer network approach for solution-processed green PHOLEDs. Journal of Materials Chemistry C 2018; 6(29), 7750-7758. https://doi.org/10.1039/C8TC01435C

48- Ren, D, Chen, L, Yuan, Y, Li, K, Xu, M, Liu, X. Designing and Preparation of Fiber-Reinforced Composites with Enhanced Interface Adhesion. Polymers 2018; 10, 1128 https://doi.org/10.3390/polym10101128

49- Haloi, DJ, Koiry, BP, Mandal, P. et al. Synthesis and characterization of poly(2-ethylhexyl acrylate) prepared via atom transfer radical polymerization, reverse atom transfer radical polymerization and radical polymerization, J. Chem. Sci. 2013 125, 791-797. https://doi.org/10.1007/s12039-013-0438-2

50- Czech Z, Kowalczyk A, Kabatc J, Świderska J. Thermal stability of poly(2-ethylhexyl acrylates) used as plasticizers for medical application, Polym. Bull. 2013; 70, 1911-1918. https://doi.org/10.1007/s00289-012-0887-7

51- Haloi DJ, Ata S, Singha NK, Jehnichen D, Voit P, Acrylic AB and ABA Block Copolymers Based on Poly(2-ethylhexyl acrylate) (PEHA) and Poly(methyl methacrylate) (PMMA) via ATRP, Appl. Mater. Interfaces 2012; 4, 4200-4207. https://doi.org/10.1021/am300915j

52- Wang G, Synthesis of Poly(n-butyl acrylate) Homopolymers by Activators Generated by Electron Transfer (AGET) ATRP Using FeCl3 6H2O/Succinic Acid Catalyst, Iranian Polymer Journal 2011; 20, 931-938

53- Meng B, Deng JJ, Liu Q, Wu Z, Yang W, Transparent and ductile poly(lactic acid)/poly(butyl acrylate) (PBA) blends: Structure and properties, European Polymer Journal 2012; 48, 127-135. https://doi.org/10.1016/j.eurpolymj.2011.10.009

54- Derouiche Y, Koynov K, Dubois F, Douali R, Legrand C, Maschke U, Optical, Electro-Optical, and Dielectric Properties of Acrylic Tripropyleneglycol Based Polymer Network Systems Including LCs, Mol. Cryst. Liq.Cryst 2012; 561, 124-135. https://doi.org/10.1080/15421406.2012.687149

55- Bouchikhi N, Semdani F, Alachaher Bedjaoui L, Maschke U, Elaboration of Side-Chain LiquidCrystalline) Elastomers and Study of Their Swelling Behavior in Anisotropic Solvents, Mol. Cryst. Liq.Cryst 2012; 560, 159-169. https://doi.org/10.1080/15421406.2012.663196

56-Culgi BV, The Netherlands, 12.0

57- Humphrey, W., Dalke, A. and Schulten, K., "VMD - Visual Molecular Dynamics", J. Molec. Graphics, 1996, vol. 14, pp. 33-38.

58- Hsin, J, Arkhipov, A, Yin, Y, Stone, JE, \& Schulten, K. Using VMD: An introductory tutorial. Current Protocols in Bioinformatics 2008; https://doi.org/10.1002/0471250953.bi0507s24

59- Mayo, SL, Olafson, BD, \& Goddard, WA. DREIDING: a generic force field for molecular simulations. The Journal of Physical Chemistry 1990; 94(26), 8897-8909. https://doi.org/10.1021/j100389a010

60- Fraaije, JHG, et al. Culgi manual 12.0.1, Culgi, Leiden, Netherlands. 
61- Berendsen, HJC, Postma, JPM, van Gunsteren, WF, DiNola, A., \& Haak, JR. Molecular dynamics with coupling to an external bath. The Journal of Chemical Physics 1984; 81(8), 3684-3690. https://doi.org/10.1063/1.448118

62- Sheppard, D, Terrell, R, \& Henkelman, G. Optimization methods for finding minimum energy paths. The Journal of Chemical Physics 2008; 128(13), 134106. https://doi.org/10.1063/1.2841941

63- Metatla, N, \& Soldera, A. Computation of densities, bulk moduli and glass transition temperatures of vinylic polymers from atomistic simulation. Molecular Simulation 2006; https://doi.org/10.1080/08927020601059901

64- Soldera, A., \& Metatla, N. Glass transition of polymers: Atomistic simulation versus experiments. Physical Review E 2006; 74(6), 061803. https://doi.org/10.1103/PhysRevE.74.061803 